\title{
VARIEDADE LINGUÍSTICA E ENSINO DE LÍNGUA ITALIANA: UMA EXPERIÊNCIA EM SALA DE AULA
}

\author{
Elisabetta Santoro \\ Graziele Altino Frangiotti
}

\section{RESUMO}

Este artigo apresenta uma pesquisa, cujo objetivo central foi verificar se aprendizes brasileiros, que estudam italiano em contextos de instrução formal há, no mínimo, um ano, possuem competência sociolinguística receptiva, que lhes permita identificar as variedades de italiano e os dialetos presentes em seis cenas de um filme italiano. Os resultados revelam que, no grupo pesquisado, essa competência não é suficientemente desenvolvida e sugerem que seria desejável dedicar mais espaço a esse aspecto da língua.

PALAVRAS-CHAVE: variedade linguística; ensino de italiano; competência sociolinguística.

\section{Introdução}

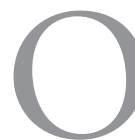

presente artigo nasce da ideia de verificar se e como se desenvolve a competência sociolinguística no processo de aquisição/aprendizagem de uma segunda língua em contexto de instrução formal, e se é possível constatar a existência de uma sensibilidade linguística relativa às diferentes dimensóes da língua aprendida. Em especial, o objetivo da pesquisa realizada foi constatar se um grupo de aprendizes brasileiros de italiano é sensível às variedades e aos dialetos, que compóem a complexa realidade linguística da Itália contemporânea. 
Para atingirmos o objetivo acima exposto, procedemos em quatro etapas: 1. aplicamos um questionário que tinha como finalidade evidenciar o perfil dos aprendizes escolhidos para a pesquisa; 2. aplicamos um $C$-test ${ }^{1}$ em língua italiana, para que pudesse ser verificado seu nível linguístico; 3 . apresentamos o filme Pane e tulipani (Silvio Soldini, Itália, 2000), selecionado por conter, nos diálogos entre seus personagens, diferentes exemplos de variedades regionais, registros e dialetos; 4 . propusemos, na aula seguinte, seis cenas extraídas do mesmo filme, pedindo, por meio de um questionário, que os aprendizes identificassem as variedades linguísticas empregadas pelos personagens.

Antes de passarmos à descrição do nível linguístico dos aprendizes, das cenas selecionadas e da metodologia de pesquisa escolhida, traçaremos um breve histórico do conceito de competência sociolinguística para melhor entendermos como ele tem sido entendido no âmbito das pesquisas em ensino/aprendizagem de segundas línguas. Além disso, apresentaremos um quadro da situação linguística na Itália contemporânea para evidenciar suas especificidades.

\section{A competência sociolinguística}

Até meados dos anos 60 do século passado, a Linguística se ocupava do estudo da língua, considerando-a um sistema abstrato, destituído de qualquer relação com a comunidade linguística que a utilizava ${ }^{2}$. Desse modo, para a ciência linguística de então, as explicaçóes para os fenômenos linguísticos precisavam ser buscadas dentro do próprio sistema da língua, pois não se considerava a relação entre esse sistema e seus usuários reais.

A partir de 1966, após a publicação da obra The social stratification of English in New York City, de William Labov ${ }^{3}$, começa-se, no entanto, a rever

1 Um C-test é um teste escrito, desenvolvido para verificar o domínio geral em uma língua estrangeira. Consiste em, no mínimo, cinco textos, contendo de 20 a 25 lacunas, criadas apagando a segunda metade das palavras, para garantir que apenas uma soluçáo seja aceitável. Os primeiros exemplos de $C$-test foram desenvolvidos para o inglês e o alemão por Christine Klein-Braley e Ulrich Raatz na Universidade de Duisburg, em 1981 (KLEIN-BRALEY, Christine; RAATZ, Ulrich. "Der C-Test: Ein neuer Ansatz zur Messung von allgemeiner Sprachbeherrschung”. AKS Rundbrief, 4: 23-37, Duisburg, 1982).

2 SANTIPOLO, Matteo. Dalla sociolinguistica alla glottodidattica. Torino: UTET Università, 2002. p. 7.

3 LABOV, William. The social stratification of English in New York City. Washington DC: Center for Applied Linguistics, 1966. 
o lugar da sociedade nos estudos linguísticos. De fato, esse estudo mostrou a dependência - até então não levada em consideração - entre os fatos sociais e os fatos de língua, na medida em que comprovou que variaçóes sociais na estrutura da comunidade nova-iorquina exerceram pressão sobre a estrutura da língua, originando os chamados fenômenos de variação linguística.

Em decorrência de tal comprovação, a Linguística puramente teórica, que se interessava somente pela caracterização do sistema linguístico, isolando-o de seu uso concreto, passou a ser também Linguística funcional, cujos esforços foram direcionados no sentido de compreender a estrutura da atividade linguística, ou seja, o uso que as diversas comunidades fazem de seu respectivo código linguístico.

É em grande medida devido a essa mudança de perspectiva que, em 1971, Dell Hymes ${ }^{4}$ afirma que o ser humano seria dotado de uma competência comunicativa formada por dois subcomponentes: a competência linguística e a competência sociolinguística. Segundo ele, a primeira dessas competências diria respeito à aprendizagem das regras linguísticas propriamente ditas, ou seja, seria uma competência referente à estrutura da língua, enquanto a segunda seria relativa à nossa capacidade de aprender a adequar o que dizemos ao contexto social no qual se dá a comunicação.

Diante desse novo olhar lançado sobre o conceito de língua e de competência, outras disciplinas tentaram incorporar às suas teorias de base uma concepção de língua que contemplasse a dimensão social e a variação a ela inerentes. Uma das disciplinas influenciadas por esse pensamento foi, justamente, a que se dedica ao ensino/aprendizagem de línguas, que via a língua como um conjunto de regras fixas a serem aprendidas, e passou a enxergá-la como um objeto de ensino multidimensional e passível de variação.

De fato, a noção de competência apresentada por Hymes representou uma grande mudança no modo de conceber os estudos linguísticos e vigorou com grande força no campo do ensino/aprendizagem de segundas línguas até o início da década de 80, quando foi revisitada e complementada pelos estudiosos Canale e Swain, no artigo intitulado "Theoretical bases of communicative approaches to second language teaching and testing"'.

4 HYMES, Dell. Pidgnization and creolization of languages. Cambridge: Cambridge University Press, 1971.

5 CANALE, Michael; SWAIN, Merrill. "Theoretical basis of communicative approaches to second language teaching and testing”. Applied Linguistics, 1, n. 1: 1- 48, 1980. 
Para esses dois autores, que refletem sobre a língua do ponto de vista da pedagogia de línguas segundas e estrangeiras, o aprendiz deve ser preparado ao longo do processo de aprendizagem, para que seja capaz de produzir enunciados na língua alvo que sejam estruturados de modo a respeitar tanto as regras do sistema linguístico aprendido (competência gramatical), quanto as regras sociolinguísticas (competência sociolinguística), e também para que esteja apto a se desvencilhar de situaçóes difíceis para as quais não possua ainda competência suficiente (competência estratégica).

Em 1983, Canale revê o que havia escrito anos antes e opera uma alteração nesse modelo inicialmente proposto, dividindo a competência sociolinguística em sociolinguística e discursiva, com esta última que concerne ao "domínio em combinar formas gramaticais e significados para obter textos de diferentes gêneros, orais ou escritos, unificados." 6

$\mathrm{Na}$ década de 90, outros teóricos refletiram sobre essa definição, construindo esquemas cada vez mais elaborados. É o caso de Lyle Bachman ${ }^{7}$, que propóe uma descrição bastante refinada de competência comunicativa, pensando-a, porém, pela perspectiva da elaboração de avaliações, e Marianne Celce-Murcia ${ }^{8}$, que, em 1995, propóe um modelo composto pelas competências linguística, estratégica, sociolinguística, acional e discursiva, modificando-o, em 2005, com a alteração de alguns nomes e a inserção de outros subcomponentes. Com esse novo modelo, temos, portanto, uma configuração que prevê as seguintes competências: sociocultural, linguística, discursiva, interacional, estratégica e formulaica.

Como é possível notar, olhar para o histórico de como foram definidas as diferentes competências no âmbito dos estudos de aquisição de segundas línguas mostra a insistência com a qual se tem tentado produzir esquemas

6 "[...] mastery of how to combine grammatical forms and meanings to achieve a unified spoken or written text in different genres." (Todas as traduçóes do inglês e do italiano contidas no presente artigo são de nossa autoria). CANALE, Michael. "From communicative competence to communicative language pedagogy”. In: RICHARDS, J. C.; SCHMIDT, R. W. Language and communication. London: Longman, 1983, p. 9.

7 BACHMAN, Lyle F. "Communicative language ability”. Trad. Niura Maria Fontana e Ver. Isabel Maria Paese Pressanto. Linguagem \& ensino, 6, n. 1: 77-128, Pelotas, jan-jun. 2003.

8 CELCE-MURCIA, Marianne. "Rethinking the role of communicative competence in language teaching”. In: SOLER, E.A.; JORDÀ, M.P.S. Intercultural language use and language learning. University of California: Springer. 2007, p. 41-57. 
cada vez mais complexos, para formular arcabouços teóricos que possam esclarecer com maior exatidão o que o aprendiz deve saber para se poder dizer competente comunicativamente e, como consequência, o que, como professores, devemos incluir em nossas aulas para que esse processo ocorra de forma a satisfazer tais necessidades.

Reflete a preocupação em incorporar as diferentes competências ao ensino/aprendizagem de línguas também o Quadro europeu comum de referência para as linguas (QECR) ${ }^{9}$, que se situa no interior das políticas linguísticas desenvolvidas pelo Conselho da Europa, tendo como objetivos centrais: fornecer uma base comum para a elaboração de programas de ensino de segundas línguas, linhas de orientação curriculares e análise de manuais; e descrever o que os alunos devem aprender e quais conhecimentos e capacidades têm de desenvolver para serem eficazes em sua atuação ${ }^{10}$.

Com vistas a descrever o conhecimento que o aprendiz de língua deve desenvolver, o QCER insere o conceito de competência comunicativa, entendendo-o como o resultado da ação de três subcomponentes: a competência linguística, a pragmática e a sociolinguística.

A primeira dessas competências inclui os conhecimentos "fonológicos, sintáticos e lexicais, bem como outras dimensóes da língua enquanto sistema, independentemente do valor sociolinguístico da sua variação e das funções pragmáticas e suas realizações." ${ }^{11}$

Já a competência pragmática diz respeito ao uso funcional dos recursos linguísticos (produção de funçôes linguísticas e atos de fala), ao emprego da coesão, da coerência, da ironia e da paródia ${ }^{12}$.

A última das competências refere-se à sociolinguística, o cerne da nossa pesquisa, que, segundo o QCER, diz respeito:

[...] às condiçốes socioculturais do uso da língua. Sensível às convençóes sociais (regras de boa educaçáo, normas que regem as

9 CONSELHO DA EUROPA. Quadro europeu comum de referência para as línguas: aprendizagem, ensino, avaliação. Trad. Maria Joana Pimentel do Rosário e Nuno Verdial Soares. Porto/Lisboa, 2001.

10 Idem, p. 19.

11 Idem, p. 34.

12 Idem, p. 35. 
relações entre geraçôes, sexos, classes e grupos sociais, codificação linguística de certos rituais fundamentais para o funcionamento de uma comunidade), a componente sociolinguística afecta fortemente toda a comunicação linguística entre representantes de culturas diferentes, embora os interlocutores possam não ter consciência desse facto. ${ }^{13}$

Além disso, essa competência inclui a capacidade de reconhecer marcadores linguísticos, tais como: léxico, morfossintaxe, características suprassegmentais e paralinguísticas, que permitam identificar falantes de diferentes classes sociais, origens regionais, origens nacionais, grupos étnicos e grupos profissionais $^{14}$.

Motivados, exatamente, por essa definição de competência sociolinguística, segundo a qual os aprendizes teriam de reconhecer e produzir elementos linguísticos levando em consideração "os marcadores linguísticos de relaçóes sociais, as regras de delicadeza, as expressóes de sabedoria popular, as diferenças de registros, os dialetos e os sotaques" ${ }^{15}$, propomo-nos, depois de mais de uma década da publicação do QCER, a verificar se aprendizes desenvolvem, como almejavam seus autores, tais habilidades e se estão, de fato, preparados para detectarem as diferentes origens regionais, os registros, os dialetos e a língua falada por estrangeiros.

Como já dissemos, nossa pesquisa refere-se às variedades da língua italiana e foi realizada com um grupo de aprendizes brasileiros em contexto de instrução formal.

\section{A arquitetura do italiano}

Como já dito anteriormente, os estudos de Labov mostram uma nova maneira de buscar na sociedade explicaçôes para os fenômenos linguísticos, fundando assim a Sociolinguística como disciplina científica. Desde então, muito se tem feito no sentido de caracterizar as línguas, partindo dos seus

\footnotetext{
13 Idem, p. 35.

14 Idem, p. 35.

15 Idem, p. 135.
} 
múltiplos usos sociais e observando como cada língua se diferencia, dando origem às ditas variedades. Partindo dos estudos da Sociolinguística italiana, apresentamos brevemente a seguir quais são as variedades que compóem o repertório linguístico italiano.

Antes de mais nada, é necessário dizer que os estudos sociolinguísticos pressupóem que a variação linguística ocorre em quatro dimensôes: 1. no tempo; 2. no espaço; 3. nos contextos de uso da língua; e 4. na estrutura da sociedade. Dado que o estudo aqui proposto é concebido em uma perspectiva sincrônica, deixaremos de lado o primeiro dos níveis de variação, aquele relativo ao tempo, e passaremos a explicitar como as demais dimensóes atuam no sistema da língua italiana.

A variação no espaço ou diatópica se dá quando uma mesma língua assume características diferentes de acordo com o local no qual é falada, sendo marcada, em primeiro lugar, pelas diferenças relativas ao plano fonético e, posteriormente, pelo plano morfossintático e lexical. No caso específico do italiano, as variedades regionais são divididas em três grupos de variedades maiores: 1 . o grupo setentrional, que é considerado por muitos o mais próximo do standard $^{16}$

16 Os linguistas italianos utilizaram a denominação standard para a língua considerada "padráo". Para defini-la, Sobrero e Miglietta afirmam que "se refere a um conjunto de regras, normas e preceitos elaborados pelos gramáticos, propostos-impostos pela escola com a etiqueta de 'formas corretas' e transmitidas de geração em geração pelas gramáticas prescritivas - ou normativas - escolares. São normas e preceitos escolhidos com o critério da respondência a um modelo ideal, sobretudo de tipo conservador." [ "[...] si riferisce a un insieme di regole, norme e precetti elaborati dai grammatici, proposti-imposti dalla scuola con l'etichetta di forme corrette' e trasmessi di generazione in generazione dalle grammatiche prescrittive - $o$ normative - scolastiche. Sono norme e precetti scelti con il criterio della rispondenza a un modello ideale, per lo più di tipo conservativo.'] (SOBRERO, Alberto A.; MIGLIETTA, Annarita. Introduzione alla linguistica italiana. Roma-Bari: Laterza, 2006. p. 61). De acordo com os dois estudiosos, o standard italiano constitui uma norma ideal que não corresponde a nenhuma variedade encontrada efetivamente no território itálico, nem mesmo à florentina que a originou, dado que, com o tempo, até a estrutura dessa variedade mudou, distanciando-se das normas da gramática prescritiva. É por isso que os linguistas italianos procuraram denominaçôes para o italiano realmente falado e escrito, identificando traços fonéticos, lexicais e morfossintáticos que o diferenciariam do standard. Francesco Sabatini propôs que se chamasse italiano dell'uso medio [italiano do uso médio] e, pouco mais tarde, Gaetano Berruto sugeriu neo-standard (SABATINI, Francesco. "L'italiano dell'uso medio: una realtà tra le varietà linguistiche italiane”. In: HOLTUS, G.; RADTKE, E. (orgs.), Gesprochenes Italienisch in Geschichte und Gegenwart. Tuebingen: Narr, 1985 e BERRUTO, Gaetano. Sociolinguistica dell'italiano contemporaneo. Roma: La Nuova Italia Scientifica, 1987). 
e que goza, portanto, de maior prestígio; 2. o grupo toscano, que é tido como variedade de prestígio somente em seu território de referência; 3. centro-meridional, que constitui o grupo dotado de menor prestígio, sendo com frequência objeto de preconceito linguístico.

Já no que diz respeito ao uso da língua em diferentes contextos comunicacionais, a chamada variação diafásica, Maurizio Dardano ${ }^{17}$ afirma que, em italiano, existem oito registros principais: áulico, culto, formal (ou oficial), médio, coloquial, informal, popular e familiar, os quais devem ser empregados de acordo com a situação e com o papel assumido pelo falante e pelo destinatário no momento da comunicaçáo.

A quarta e última dimensão da variação é a que se verifica na estrutura da sociedade. Nesse sentido, em italiano, pode-se dizer que existem pelo menos quatro variedades relacionadas a esse nível: 1. a variedade popular, que, de acordo com linguistas italianos, pode ser definida "de maneira geral, como o modo de se expressar de um inculto que, diante da necessidade de se comunicar e sem treinamento, manipula a língua nacional" ${ }^{18}$; 2. o italiano culto, usado por falantes de nível sociocultural médio-alto e alto, que coincide, grosso modo, com o standard italiano; 3. o italiano dos jovens, que é a variedade utilizada por indivíduos de 13 a 21 anos, caracterizada por gírias, variantes diatópicas e itens lexicais típicos dos dialetos italianos; e 4. as línguas especiais, marcadas por traços lexicais e empregadas em determinados setores, como a medicina, a arquitetura, a engenharia, a biologia, entre outros.

Além da descrição das diferentes variedades já abordadas, cabe-nos ainda mencionar duas questôes bastante peculiares na configuração linguística italiana: os dialetos e a língua dos imigrantes.

No que se refere à presença de dialetos no território italiano, é importante, em primeiro lugar, diferenciar a noção de dialeto aqui adotada daquela utilizada, por exemplo, nos estudos de língua inglesa. Para tanto, lançamos mão da seguinte explicação fornecida por Matteo Santipolo:

17 DARDANO, Maurizio. Manualetto di linguistica italiana. Bologna: Zanichelli, 1991.

18 "[...] in maniera generale come il modo di esprimersi di un incolto che, sotto la spinta di comunicare e senza addestramento, maneggia la lingua nazionale. "COVERI, Lorenzo; BENUCCI, Antonella; DIADORI, Pierangela. Le varietà dell'italiano: manuale di sociolinguistica italiana. Roma: Bonacci, 1998. p. 96. 
em italiano, (sic) (analogamente ao alemão) “dialeto" indica uma das línguas regionais faladas na Itália, ou seja, autônomas em relação ao italiano standard. Em inglês, ao contrário, o termo se refere a uma variedade local da língua standard. Em outras palavras, isso significa que quando um italiano se refere a um dialeto, de fato está pensando em uma língua independente do italiano e estruturalmente muito distante (por exemplo, os da Calabria, de Bergamo, da Apúlia ou de Gênova); enquanto um inglês tem em mente uma variedade do standard, que pode diferenciar-se pelo acento, alguns lexemas ou outras características de qualquer maneira não muito profundas ou estruturais. ${ }^{19}$

Estudos dialetológicos realizados na Itália demonstram que o uso do dialeto tem diminuído com o passar do tempo, ampliando-se, cada vez mais, as situaçóes comunicativas nas quais se opta pela língua nacional. Todavia, existe ainda o que os linguistas designam como diglossia, ou seja, os usuários da língua escolhem um ou outro código de acordo com o contexto. Assim, para usos formais (e, sobretudo, escritos) é escolhida a norma standard do italiano, enquanto para os informais, especialmente se a comunicação ocorre entre membros da mesma família ou entre amigos, prefere-se o dialeto.

Além do dialeto, temos ainda a questão do italiano falado por imigrantes, que é a variedade de italiano utilizada por estrangeiros, os quais, em território italiano, muitas vezes aprendem a língua em contexto espontâneo, ou seja, a partir do contato direto com falantes nativos e sem instrução formal, o que resulta em uma variedade simplificada e reelaborada do sistema linguístico da língua alvo.

A rápida apresentação que fizemos da realidade linguística italiana mos-

19 “[...] in italiano, (sic) (analogamente al tedesco) 'dialetto' indica una delle lingue regionali parlate in Italia, ossia autonome rispetto all'italiano standard. In inglese, invece, il termine si riferisce a una varietà locale della lingua standard. In altre parole, ciò significa che quando un italiano si riferisce a un dialetto di fatto sta pensando a una lingua autonoma dall'italiano e da esso strutturalmente anche molto distante (ad esempio il calabrese, il bergamasco, il pugliese o il genovese); mentre un inglese ha in mente una varietà dello standard che può differenziarsi da esso per accento, qualche lessema o altre caratteristiche comunque non troppo profonde o strutturali." SANTIPOLO, Matteo. Op. cit., p. 28. 
tra a sua complexidade, consequência das variedades e até mesmo das diferentes línguas (os dialetos) que a constituem. O filme selecionado para a pesquisa dá conta de parte dessa realidade, o que nos permitiu observar e submeter aos aprendizes que participaram da pesquisa os registros áulico, formal e coloquial, a variedade regional meridional, os dialetos vêneto e abruzês e o italiano falado por imigrantes.

A seguir, serão apresentados os procedimentos metodológicos utilizados durante o desenvolvimento da pesquisa e a descrição das cenas selecionadas para o julgamento dos aprendizes.

\section{A experiência em sala de aula: os aprendizes e o filme}

Para escolher o tipo de pesquisa que seria realizada, partimos do pressuposto que é na recepção que a competência sociolinguística pode se manifestar em sua total amplitude, já que um aprendiz pode saber distinguir, em sua produção, entre os registros da segunda língua, mas não, por exemplo, falar utilizando diferentes variedades regionais. Nossa pesquisa concentrou-se, portanto, na recepção, e se propôs a verificar se aprendizes brasileiros de italiano, em contexto de instrução formal, seriam capazes de reconhecer as variedades do sistema linguístico italiano e de diferenciar o italiano dos dialetos.

Contamos com a colaboração de um grupo de aprendizes composto por 12 alunos matriculados em um curso de conversação do projeto de extensão universitária da Universidade de São Paulo chamado Italiano no Campus, que oferece cursos de língua e cultura italianas, abertos à comunidade e ministrados por pós-graduandos da mesma instituição.

A partir da aplicação de um questionário, que antecedeu a realização da pesquisa, traçamos um perfil dos aprendizes ${ }^{20} \mathrm{e}$, em especial, constatamos que, entre eles, sete frequentavam os cursos oferecidos no Italiano no Campus há

20 O grupo era constituído por onze mulheres e um homem, de idade entre 51 e 74 anos. Todos declararam estudar a língua italiana apenas por prazer e interesse pessoal. Dez dos 12 aprendizes afirmaram que nunca haviam estudado italiano antes de começarem o curso no Italiano no Campus, enquanto duas aprendizes já haviam estudado a língua antes: uma em um curso de italiano instrumental e a outra, em um instituto, mais de 50 anos antes do início da nossa pesquisa. 11 aprendizes eram aposentados e apenas uma, advogada, ainda exercia a profissão. 
mais de quatro anos e outros seis estudavam a língua italiana há menos de dois anos e meio, sendo que o menor tempo de estudo era de um ano.

Tendo em vista essas disparidades, para que pudéssemos verificar se diferiam também os conhecimentos linguísticos dos alunos, aplicamos um $C$-test, pensado para quem estuda a língua há aproximadamente um ano (nível entre A2 e B1 do QCER). Os resultados foram os seguintes:

Tabela 1 - Resultado do C-test

\begin{tabular}{|l|l|l|}
\hline ALUNO & $\begin{array}{l}\text { Anos de estudo } \\
\text { de italiano }\end{array}$ & $\begin{array}{l}\text { Lacunas preenchidas } \\
\text { corretamente }\end{array}$ \\
\hline 1 & 5 & 71 \\
\hline 2 & 5 & 50 \\
\hline 3 & 5 & 73 \\
\hline 4 & 4,5 & 70 \\
\hline 5 & 4 & 56 \\
\hline 6 & 4 & 70 \\
\hline 7 & 3 & 54 \\
\hline 8 & 3 & 33 \\
\hline 9 & 2,5 & 44 \\
\hline 10 & 2 & 43 \\
\hline 11 & 1 & 71 \\
\hline 12 & 1 & 81 \\
\hline
\end{tabular}

Como mostra a tabela acima, a média atingida não foi uniforme, pois quatro dos seis aprendizes, que estudavam italiano há mais de quatro anos no momento da aplicação do teste, preencheram corretamente de 70 a 73 lacunas, enquanto quatro dos seis aprendizes que estudam a língua há menos tempo obtiveram entre 33 e 54; dois alunos que já estudavam italiano há quatro anos ou mais acertaram 50 e 56 lacunas, sendo que os dois aprendizes que estudavam italiano há exatamente um ano, o menor tempo de todos, conseguiram um elevado número de acertos, 81 e 71.

De qualquer maneira, tanto o tempo de estudo e, portanto, de exposição à língua, quanto o nível linguístico identificado por meio do $C$-test são fatores que foram levados em conta na análise dos resultados da pesquisa e que retomaremos mais adiante. 
Passemos agora à descrição do filme selecionado para a pesquisa. A protagonista é Rosalba, uma dona de casa de Pescara (cidade do Sul da Itália) que, em uma excursão de ônibus com a família, é esquecida em um posto de abastecimento, no qual o ônibus faz uma de suas paradas. Sem dinheiro, ela decide pegar carona com desconhecidos para voltar à sua cidade, mas no caminho muda de ideia e opta por ir até Veneza, a cidade dos seus sonhos, e tirar "férias" da família e da rotina.

Como dissemos anteriormente, a escolha do filme foi motivada pela presença de diversas variedades regionais e dialetos, com os quais se defronta a protagonista Rosalba ao longo de sua viagem do Sul ao Norte da Itália. Além disso, o filme propicia a observação de outros fenômenos linguísticos como, por exemplo, o italiano áulico falado por Fernando Girasole, um islandês que mora em Veneza e que, incapaz de diferenciar, usa esse registro, em todos os contextos comunicativos; ou ainda as peculiaridades linguísticas de Goran Yakovic, também estrangeiro, que, não tendo adquirido por completo a língua, formula enunciados simplificados, inclusive desrespeitando o sistema linguístico italiano.

Após assistir ao filme, para que os aprendizes conhecessem a função de cada personagem na trama, suas proveniências e o desenvolvimento da história, foram propostas seis cenas extraídas do filme, selecionadas porque continham os fenômenos linguísticos que queríamos submeter ao seu julgamento.

Para cada cena, foi pedido aos aprendizes que preenchessem uma ficha, na qual deviam assinalar se o enunciado produzido pelo personagem indicado era:

Tabela 2 - Variedades de italiano nas cenas selecionadas

\begin{tabular}{|l|}
\hline Italiano coloquial \\
\hline Italiano formal \\
\hline Italiano áulico \\
\hline Variedade regional \\
\hline Italiano falado por estrangeiro \\
\hline Dialeto \\
\hline
\end{tabular}

Foi-lhes dito antecipadamente que a uma mesma cena poderia corresponder mais de uma alternativa correta e que eles deveriam, após identificar o italiano/dialeto empregado, justificar, expondo a razão de sua escolha. 
Além disso, eles deviam indicar seu grau de compreensão de cada cena, com a seguinte classificação:

Tabela 3 - Níveis de compreensão das cenas do filme

\begin{tabular}{|l|l|}
\hline Perfeito & Entendeu tudo \\
\hline Muito bom & Entendeu quase tudo \\
\hline Bom & Entendeu pelo menos o assunto do diálogo \\
\hline Insuficiente & Entendeu apenas palavras isoladas \\
\hline Nulo & Não conseguiu entender nem palavras isoladas, nem o assunto \\
\hline
\end{tabular}

Para esclarecer qual era o conteúdo das cenas e as respostas esperadas, descreveremos a seguir as seis cenas selecionadas com a transcrição de cada uma delas ${ }^{21}$. Observe-se que, embora nas interaçóes entre os personagens possam ser notados com frequência duplos sentidos e equívocos que criam efeitos de sentido de humor, não entraremos aqui na descrição desses detalhes.

$\mathrm{Na}$ primeira cena, estamos ainda no início do filme. A protagonista Rosalba deixa um recado para a sua família em uma secretária eletrônica:

Rosalba: ciao sono io:: eh \# volevo dirvi che: \# ho perso il treno e::: sono a Venezia ehmm comunque dentro il forn-, dentro il congelatore ci sta la pasta al forno se voi la mettete dieci minuti nel forno a microonde è pronta \# mi dispiace tanto::: comunque io ritorno domani alle::: alle tre e mezza:: [un att-] precisamente alle 15,28 \# baci a tutti. ${ }^{22}$

21 As transcriçôes das cenas selecionadas para a pesquisa foram baseadas no sistema jeffersoniano, que foi, contudo, simplificado. Foram evidenciados essencialmente pausas (\#) e prolongamentos vocálicos (:::). O italiano estará em itálico, enquanto será utilizado o redondo para elementos claramente pertencentes ao dialeto ou a uma variedade "estrangeira”. Depois de cada transcrição, colocamos, em nota de rodapé, a tradução das cenas em português, com o objetivo de facilitar a compreensão. Nas traduções, foram eliminados os sinais diacríticos e foi utilizada a pontuação, excluída nas transcriçóes. Nas transcriçóes, foram mantidos apenas os pontos de interrogação, assim como as maiúsculas para nomes próprios. Nas traduçôes, privilegiou-se o sentido e foram excluídas também as peculiaridades linguísticas dos personagens.

22 [Oi sou eu. Eu queria dizer que perdi o trem e estou em Veneza. De qualquer maneira no forn-, no congelador tem um macarrão para fazer no forno. Se vocês colocarem dez minutos no microondas, vai ficar pronto. Sinto muito. De qualquer maneira, eu volto amanhã às três e meia [um seg-] exatamente às 15,28. Beijos para todo mundo.] 
Para essa cena, o objetivo era verificar se os aprendizes percebiam que Rosalba emprega uma variedade regional meridional, perceptível no seu sotaque e na escolha da forma verbal " $c i s t a$ ", bastante difundida na regiâo Sul da Itália no lugar do mais neutro “' $e$ ”, e se observavam, também, que o registro é coloquial, já que ela está deixando uma mensagem para familiares. Esperava-se, então, que os aprendizes assinalassem duas alternativas: variedade regional e italiano coloquial.

A segunda cena selecionada tinha como foco Mimmo, o marido de Rosalba, e se divide em dois momentos: o primeiro, no qual ele fala com seu advogado por telefone; o segundo, no qual ele conversa frente a frente com seu sócio. Na primeira parte da cena, conversando com o advogado, ele diz:

Mimmo: e e:: secondo te è una cosa normale che una piglia acchiappa e se ne va accussì:: \# ma com'è possibile da un punto di vista legale non si può fa' niente? \# ah seh:: ci manca solo che mi faccio spella' da nu detectiv' privato bella pensata grazi' bravo bravo ce ne fossero avvocati:: grazie avvocato ciao ciao si va buo' ciao ciao. ${ }^{23}$

Nessa primeira parte da cena, o marido de Rosalba pede um conselho a seu advogado, que, no entanto, parece sugerir apenas a contratação de um detetive. Ele, irritado, responde ao advogado, alternando variedade regional meridional e dialeto, e se despede. Na sequência dessa cena, enquanto Mimmo está observando uma foto sua e de sua esposa, entra o seu sócio, que diz:

Sócio: Mimmo:: io sto andando a Civitella per gli infissi di quell'asilo: \# senti:: fuori c'e l'idraulico che ci ha mandato Di Matteo, e che fa'? te la vedi tu? ah:: novità? ${ }^{24}$

Aqui, o sócio utiliza um italiano sem evidentes marcas regionais para se comunicar com Mimmo e conclui sua fala perguntando indiretamente sobre sua esposa. É nesse momento que o marido de Rosalba, muito nervoso, responde:

23 [E você acha que é uma coisa normal que uma pega e vai embora assim, mas como é possível do ponto de vista legal não dá para fazer nada? Ah, só me falta ter que pagar o olho da cara para um detetive... Mas que boa ideia, obrigado, muito bem, muito bem, ah, se tivesse advogados... obrigado... advogado, tchau tchau, sim, certo, tchau tchau.]

24 [Mimmo eu estou indo para Civitella para os batentes daquela creche. Escuta, lá fora está o encanador que Di Matteo mandou para nós. O que você vai fazer? Você vai cuidar disso? Ah, novidades?] 
Mimmo: Senti facciamo una cosa:: se tengo qualche novità te la veng' a dic'jo. Va buo'? Sócio: Va buo'. ${ }^{25}$

Além do sotaque meridional fortemente marcado com o qual o marido de Rosalba responde ao sócio, observa-se o uso de contraçóes e de termos dialetais. Assim, a expectativa era que os aprendizes reconhecessem não apenas uma variedade tipicamente regional, mas também a presença bastante patente do dialeto.

A terceira cena enfocava dois personagens que falam um italiano de registro formal, bastante próximo ao italiano dito standard. Nesse diálogo, o personagem Costantino, que na verdade é encanador, mas é contratado por Mimmo como detetive para descobrir o paradeiro de sua esposa, chega a Veneza, onde encontra um captador de clientes, que tenta convencê-lo a reservar um quarto em um dos hotéis que representa. Eis o diálogo entre eles:

Representante: scusi::? se fossi in lei non ne sarei tanto sicuro:: permette::?

Costantino: come ha detto scusi?

$\underline{\mathrm{R}}$ : la prima volta a Venezia?

C: si perché?

$\underline{\mathrm{R}}$ : glielo dico io:: prima di settembre non la trova!

C: e lei che ne sa?

$\underline{\mathrm{R}}$ : sono del settore.

C: pure lei?

$\underline{\mathrm{R}}$ : mica da ieri:: guardi là \#

C: beh?

R: come beh? e secondo lei tutta quella gente li in fila che ci sta a fare? cerca una sta:nza come lei \#

$\mathrm{C}$ : non si trovano?

$\underline{\mathrm{R}}$ : non mi crede? Tiene telefoni ma lei quanto vuole spendere?

C: eh non piu di 50 al giorno \#

R: ah 50 mila lira al giorno a Venezia di questi tempi.

C: 50 quella è la disponibilità più non ne tengo 50.

$\underline{\mathrm{R}}$ : ho quello che fa per lei. ${ }^{26}$

25 [M: Escuta, vamos fazer uma coisa, se tenho alguma novidade, eu próprio falo, tá? S: Tá.]

26 [Representante: Com licença. No seu lugar, eu não teria tanta certeza, posso?/Costantino: $\mathrm{O}$ que o senhor disse, desculpe?/R: É a primeira vez que está aqui em Veneza?/C: Sim, por 
Pela relação existente entre os dois personagens, são utilizados o registro formal e a forma de tratamento de cortesia, identificável pela conjugação dos verbos na terceira pessoa do singular ("ha detto", "trova", "sa") e pela presença de pronomes também de terceira pessoa, como "lei" e "glielo". Os aprendizes deveriam ter selecionado como resposta correta a variedade formal, por reconhecerem a forma de tratamento utilizada.

A quarta cena, assim como a anterior, é construída ao redor do detetive Costantino. Nesse momento, ele está na frente do hotel no qual vai ficar hospedado e encontra Goran Yakovic, o guia turístico estrangeiro responsável por apresentar-lhe seu quarto e por receber antecipadamente o valor referente a uma semana de hospedagem. O diálogo entre os dois se desenvolve da seguinte maneira:

Yakovic: signorrre:: bene arrivato:: uh lascia porto io di valigio sei trovato facile strada? principale spiegato bene? si mappa città pianta chiave stanza bar prego tevì se ce l'hai qualcuno problema \# questo è mio telefono numero::: porta chi vuole non paghi di più. Una settimana anticipo trecentocinquantamilo soldi a mano prego.

Costantino: si si ma questo non è n'albergo eh?

Y: tu cambio idea niente problema tu cerca altro hótel.

C: aspetta! sta compresa la colazione? ${ }^{27}$

No filme, não é explicitada a origem de Goran Yakovic, mas seu nome e seu sotaque fazem supor que seja de um país do Leste Europeu. Nessa cena, os aprendizes teriam elementos para identificar que Yakovic não é italiano, em primeiro

quêe/R: Eu digo para o senhor: antes de setembro não a encontra!/C: E como o senhor

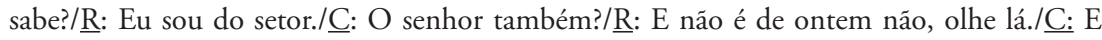
daí?/R: Como: e daí? E o que o senhor acha que todo aquele pessoal lá na fila está fazendo? Está procurando um quarto, como o senhor./․: Não tem quartos?/R: O senhor não acredita em mim? Pegue. Telefone. Mas quanto o senhor quer gastar?/C: Eh não mais de 50 por dia./R: 50 mil liras por dia, em Veneza, nessa época!/CL: 50, é isso o que eu posso pagar, mais do que isso eu não tenho./R: Eu tenho o que o senhor precisa.]

27 Yakovic: Senhor, seja benvindo. Deixe, eu pego a mala. Achou fácil o caminho? Meu chefe explicou direito? Sim, mapa cidade, chave quarto, bar, por favor, tv, se você tiver qualquer problema, esse é meu telefone. Traga quem quiser. Não se paga nada a mais. Pagamento antecipado para uma semana 350.000 cash, por favor./Costantino: Sim, sim, mas esse não é um hotel!/Y: Você mudou de ideia? Nenhum problema. Você procura outro hotel./CL: Espere! Está incluído o café da manhâ?] 
lugar, pelo nome que aparece impresso em seu cartão de visita e, mais ainda, pelo seu modo de falar. $\mathrm{Na}$ cena, há vários exemplos de simplificações ("mappa città pianta, chiave stanza, bar prego, tevü), o uso de uma ordem sintática não prevista pelo sistema da língua italiana ("porto io di valigio" ou "se ce l'hai qualcuno problema questo è mio telefono numero") e evidentes "erros", na escolha do auxiliar no tempo composto ou das desinências da segunda pessoa do singular ("sei trovato facile strada?” "Tu cambio idea niente problema tu cerca altro hotel”). A opção que deveria ser escolhida era, portanto, que se tratava do italiano de um estrangeiro.

$\mathrm{Na}$ penúltima cena, pedimos aos alunos que se concentrassem na fala da personagem chamada Adele. A cena acontece em Veneza e a jovem mulher está contando para Rosalba e Grazia Reginella (amiga e vizinha de Rosalba), como conheceu o pai de seu filho:

Grazia: sono:: la vicina di casa \# piacere:: Grazia Reginella estetista e massaggiatrice olistica.

Adele: Adele:: operaia specializzata e lui xe Eliseo.

G: Ciao!

Eliseo: Mamma mi go fame::

A: dopo xe morto anca me pare lavorava al petrolchimico, se ga ciapa' un cancro::

$\underline{\mathrm{G}}$ : quanti anni avevi?

A : quindese.

Rosalba: come hai fatto da sola?

A: ni hanno posteggiato da una zia \# a Pordenone il periodo più merdoso della mia vita le spussava el fia' de acido fenico so' scappata siè volte cosi quando l'ho incontrato \# ho pensato che el schifo già era finio, me dizeva che me voeva ben' mi \# mi ero matta per eo \# e dopo son restata 'nsinta.

R: E lui che ha fatto?

A: Sta' atento non gavevo ni ancora partorio:: che ja' el se a fazea con artra.

$\underline{\mathrm{R}}$ : oh dio non ci posso credere::

$\underline{\mathrm{G}}$ : io ormai non mi stupisco più di niente \#

R: quando è nato lui però è cambiato dopo:: no?

A: uhhh come no? s'è giocato anca i soldi della carrossina.

R: uhh madonna è mostruoso. ${ }^{28}$

28 [Grazia: Sou a vizinha, prazer, Grazia Reginella esteticista e massagista holística./Adele: Ade-

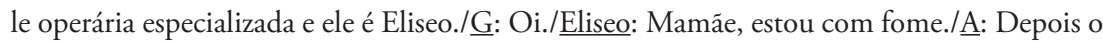
meu pai morreu também, ele trabalhava em uma indústria petroquímica, teve um câncer./G: 
Embora haja na cena três personagens interagindo, deixamos claro aos aprendizes que seria necessário classificar somente a língua falada por Adele, partindo do pressuposto que perceberiam o uso, em vários momentos, do dialeto vêneto, tanto pela pronúncia, quanto pelos elementos lexicais e morfossintáticos.

$\mathrm{Na}$ última cena selecionada, aparece o islandês Fernando, que ameaça Costantino com uma arma antiga, herança da família de sua ex-esposa:

Fernando: apparteneva al nonno di mia moglie \# l'ultima volta ha sparato a Caporetto \# ma come può notare è stato accuratamente preservato dall'insidia della ruggine \# e dall'usura del tempo \# al suo posto eviterei qualsiasi reazione che possa indurmi a mostrarle l'efficienza della sua meccanica.

Costantino: come ha detto, scusi? ${ }^{29}$

A expectativa aqui era que os aprendizes identificassem duas características diferentes: que Fernando é estrangeiro e que, também por causa disso, usa, em um contexto inapropriado, um registro de italiano que pode ser definido áulico. De fato, a seleção lexical e as estruturas morfossintáticas utilizadas caracterizam a língua escrita e são tão rebuscadas que chegam a ser incompatíveis com o italiano falado, como demonstra também a reação de estranhamento contida na resposta de Costantino.

Passaremos agora à última parte do trabalho dedicada à apresentação dos resultados da pesquisa realizada.

Quantos anos você tinha?/ㅁ: Quinze./Rosalba: Como você fez sozinha?/A: Me levaram para viver com uma tia, em Pordenone, o período mais horrível da minha vida, o hálito dela fedia a ácido fênico, fugi seis vezes. Assim, quando eu o encontrei, achei que a nojeira já tinha acabado, ele dizia que me amava, eu era louca por ele. E depois fiquei grávida./R: E o que ele fez?/A: Presta atenção. Não tinha nem chegado a criança e ele já estava com outra./R meu Deus, não acredito nisso./G: Eu não me surpreendo mais com nada./ㅁ: Mas quando ele nasceu, ele mudou, não é?/A: Ah claro, ele perdeu no jogo até o dinheiro do carrinho do bebê./R: Uhh minha nossa Senhora, é monstruoso.]

29 [Fernando: Pertencia ao avô da minha esposa. A última vez que disparou foi em Caporetto. Mas como pode notar, foi cuidadosamente protegida das armadilhas da ferrugem e da deterioração causada pelo tempo. No seu lugar, evitaria qualquer reação que possa me induzir a mostrar-lhe a eficiência de sua mecânica./Costantino: Desculpe, o que foi que o senhor disse?] 


\section{Resultados}

Alguns dos aprendizes que participaram da pesquisa afirmaram ter tido dificuldade na realização da tarefa de identificar as variedades linguísticas do italiano e os dialetos. Em sua avaliação, isso dependia da insuficiente compreensão das falas dos personagens, o que pode ser consequência de um restrito contato com o italiano falado, limitado provavelmente à sala de aula, onde, em geral, os docentes podem recorrer a estratégias como perífrases, gestualidade, traduçóes para a língua materna dos alunos, que facilitam a compreensão.

Como foi dito na seção anterior, os aprendizes realizaram um C-test, no qual ficou comprovado que seus níveis de competência linguística não eram uniformes, o que poderia se refletir também nos resultados do nosso teste de competência sociolinguística receptiva. Todavia, o primeiro dado revelado pela análise dos resultados da pesquisa é que a sensibilidade às variedades linguísticas não parece acompanhar a competência linguística dos aprendizes, isto é, não necessariamente a um nível linguístico mais elevado corresponde uma maior competência sociolinguística.

De fato, observando o desempenho dos sete aprendizes que têm contato com a língua italiana há mais de quatro anos, constatamos que apenas um deles percebeu corretamente 4 das 9 variedades que deveriam ser identificadas, atingindo a maior quantidade de acertos do grupo, enquanto os demais, tanto os que já estudam a língua italiana há pelo menos quatro anos, quanto os que a estudam há menos de dois anos, acertaram de 1 a 3 respostas.

Com o objetivo de apresentar com maior clareza os resultados obtidos, foi preparada a tabela abaixo, na qual constam, além de uma primeira coluna com uma linha para cada cena, seis colunas com todas alternativas de variedades linguísticas propostas aos aprendizes. As seis colunas foram divididas em dois: na da esquerda um $\mathrm{X}$ indica as categorias corretas para cada cena, enquanto na da direita foi transcrito o número de indicaçôes recebidas por cada alternativa. 
Tabela 4 - Variedades linguísticas esperadas e resultados obtidos na avaliação das cenas

\begin{tabular}{|c|c|c|c|c|c|c|c|c|c|c|c|c|}
\hline & \multicolumn{2}{|c|}{ Coloquial } & \multicolumn{2}{|c|}{ Formal } & \multicolumn{2}{|c|}{ Áulico } & \multicolumn{2}{|c|}{$\begin{array}{l}\text { Variedade } \\
\text { Regional }\end{array}$} & \multicolumn{2}{|c|}{$\begin{array}{l}\text { Italiano de } \\
\text { um } \\
\text { estrangeiro }\end{array}$} & \multicolumn{2}{|c|}{ Dialeto } \\
\hline Cena 1 & X & 6 & & 2 & & 0 & $\mathbf{X}$ & 3 & & 0 & & 0 \\
\hline Cena 2 & & 3 & & 0 & & 0 & $\mathrm{X}$ & 4 & & 1 & X & 5 \\
\hline Cena 3 & & 7 & X & 2 & & 0 & & 3 & & 0 & & 0 \\
\hline Cena 4 & & 7 & & 0 & & 0 & & 1 & X & 3 & & 2 \\
\hline Cena 5 & & 4 & & 0 & & 0 & & 7 & & 3 & X & 1 \\
\hline Cena 6 & & 4 & & 7 & X & 0 & & 2 & $\mathbf{X}$ & 1 & & 0 \\
\hline
\end{tabular}

No que diz respeito à primeira cena, que retratava Rosalba deixando um recado à família, seis aprendizes assinalaram, como esperado, que a protagonista empregava italiano coloquial, enquanto outros três assinalaram a opção variedade regional e apenas dois indicaram o registro formal. Entretanto, nenhum aprendiz selecionou as duas variedades efetivamente contidas em sua fala. Na justificativa, apenas um aprendiz concluiu que o registro era coloquial porque Rosalba falava com seus familiares, enquanto os demais não conseguiram expressar justificativas adequadas.

$\mathrm{Na}$ segunda cena, quando o marido de Rosalba falava, em um primeiro momento, com o seu advogado e, posteriormente, com o seu sócio, a maioria dos aprendizes chegou a identificar a presença ou da variedade regional ou do dialeto, sendo que cinco assinalaram que o marido de Rosalba falava um dialeto e quatro disseram se tratar de uma variedade regional. Ninguém percebeu, porém, que ambas estavam corretas. Três aprendizes afirmaram não ter entendido a fala do personagem, sugerindo que a questão da compreensão pode ter influenciado a opção pelo dialeto. Essa hipótese confirma-se cruzando esses dados com as declaraçóes quanto ao grau de compreensão desse diálogo, já que sete aprendizes disseram ter compreendido apenas palavras isoladas.

$\mathrm{Na}$ cena 3, que retratava o detetive em um diálogo com o captador de clientes, esperava-se que os aprendizes identificassem elementos do registro formal, mas apenas dois o reconheceram, enquanto sete acreditaram ter ouvido o registro coloquial. Para justificar a escolha, um dos aprendizes disse que o registro era coloquial, porque havia escutado o pronome "Lei", deixando claro 
que não sabia que o pronome " $t u$ " é empregado em contextos informais, enquanto "Lei" é indício de formalidade. Ainda sobre as justificativas fornecidas, os dois aprendizes que identificaram corretamente o registro também indicaram que sua escolha era devida à presença do pronome "Lei", evidenciando, assim, sua saliência como elemento linguístico que permite distinguir entre contextos comunicativos e, portanto, entre registros, enquanto outras escolhas lexicais e o uso da terceira pessoa do verbo não são identificados.

$\mathrm{Na}$ quarta cena, ouvia-se um estrangeiro falando italiano. Apenas três estudantes indicaram a alternativa correta, sem, no entanto, conseguir explicitar a razão de sua escolha. Chamou nossa atenção a justificativa dada por um dos aprendizes que acertou a resposta: ele escreveu ter sido levado a isso por ter entendido tudo que o personagem dizia. É interessante, no entanto, observar que, embora tenha considerado o diálogo compreensível, o aluno não foi capaz de selecionar elementos linguísticos que justificassem sua escolha, confirmando nossa hipótese de que o grau de compreensibilidade dos diálogos influenciou intuitivamente as respostas dos aprendizes.

$\mathrm{Na}$ quinta cena, Adele utiliza o dialeto vêneto para contar sua história. Somente um aprendiz acertou a resposta, enquanto houve sete indicaçóes para "variedade regional", quatro para "italiano coloquial" e três para "italiano de um estrangeiro". Os resultados para essa cena diferem de forma significativa em relação à segunda cena, na qual também se falava um dialeto (o marido de Rosalba falava dialeto abruzês), reconhecido por cinco alunos. $\mathrm{O}$ único aprendiz que respondeu corretamente, no caso da cena 5 , deu como justificativa sua não compreensão daquilo que tinha sido dito, confirmando mais uma vez a hipótese de que os aprendizes tendem a associar o dialeto à dificuldade de compreensão. Entre aqueles que pensaram ter ouvido uma variedade regional, um aprendiz justificou sua escolha, dizendo que algumas palavras eram pronunciadas com um sotaque diferente do que está acostumado a ouvir e acrescentou a hipótese de que isso pudesse depender da profissão de Adele, que afirma ser operária. Isso poderia revelar que o aluno tem consciência da relação existente entre a profissão e o uso da língua. Ainda a respeito desse quinto diálogo, surpreendeu-nos que três aprendizes tenham afirmado que a variedade ouvida correspondia ao italiano falado por um estrangeiro, especialmente no caso de alguns que acreditaram ter ouvido palavras em espanhol, corroborando a distância existente entre a língua nacional e os dialetos presentes na península. 
A sexta e última cena foi introduzida para verificar se a sensibilidade às variedades linguísticas dos aprendizes os levaria a perceber que o enunciado formulado pelo islandês Fernando pertencia ao registro áulico, pois continha elementos lexicais e sintáticos típicos do registro literário e dificilmente seria utilizado por um falante nativo de italiano na oralidade. Diferente do esperado, nenhum aluno se deu conta da presença desses elementos e apenas um considerou, corretamente, que era um italiano falado por um estrangeiro, enquanto sete aprendizes acreditaram que se tratasse de italiano formal e quatro o consideraram registro coloquial. Vejamos rapidamente as justificativas. Entre os estudantes que consideraram a fala de Fernando formal, dois disseram que isso se devia à presença do pronome possessivo de terceira pessoa em " $\mathrm{al}$ Suo posto", o que confirma a hipótese de que os pronomes foram determinantes na definição do registro. Outros dois afirmaram que o personagem falava de forma pausada e "correta". Esta última afirmação nos induz a uma reflexão sobre como os aprendizes pensam a questão da norma e do uso linguístico e confirma que para alguns a língua "correta" é a do registro formal, enquanto as demais variedades seriam "corrompidas" e, portanto, menos "corretas". A seguir, as conclusôes às quais chegamos após a análise dos resultados.

\section{Conclusões}

Os resultados da pesquisa realizada mostraram que não houve disparidades significativas entre os aprendizes que estudam a língua italiana há mais tempo e os que a estudam há menos tempo. Os dados sugerem, portanto, que não há relação direta entre a competência linguística e o desenvolvimento da competência sociolinguística receptiva.

Além disso, no que se refere à capacidade de reconhecer o dialeto, parece ter sido mais simples perceber a presença do dialeto meridional, enquanto o vêneto foi considerado pela maioria variedade regional, revelando que esses aprendizes não desenvolveram uma clara percepção quanto às diferenças existentes entre variedades regionais, relacionadas essencialmente ao sotaque e às escolhas lexicais, e dialetos, que são outras línguas, com uma organização morfossintática e fonética, frequentemente, bastante distantes da italiana.

Os dados nos permitiram ainda constatar que a sensibilidade dos aprendizes quanto aos registros formal e informal é direcionada, em muitos casos, 
pelo uso dos pronomes que os aprendizes reconhecem como sinais que indicam o registro empregado. Seria, no entanto, desejável que eles fossem capazes de identificar aspectos relacionados também ao contexto no qual os diálogos ocorrem e às escolhas lexicais e morfossintáticas dos falantes.

Ainda sobre os registros presentes no repertório italiano, ficou evidente que os aprendizes não possuem elementos para diferenciar entre registro formal e áulico, pois, ao que parece, não conseguem perceber a seleção lexical e morfossintática que indica a presença do registro áulico.

Mesmo nos casos nos quais identificam corretamente a(s) variedade(s) ou o dialeto escutado, os aprendizes não conseguem expressar claramente a razão das escolhas efetuadas, pois evidentemente faltam categorias que lhes permitam fundamentá-las. É possível que isso se deva à ausência desse tipo de reflexão nos livros didáticos e, mais em geral, nas aulas de uma segunda língua, o que impede que os aprendizes desenvolvam a capacidade de observar a língua, percebendo o que a caracteriza e como muda nos diferentes contextos comunicativos.

Finalmente, pudemos constatar que os aprendizes envolvidos na pesquisa realizam suas escolhas, motivados muitas vezes pelo grau de compreensão do diálogo. Assim, quando julgam o seu grau de compreensão "bom", "muito bom" ou "perfeito", normalmente, escolhem como alternativa correta o registro coloquial ou o italiano falado por um estrangeiro e, quando julgam terem atingido uma compreensão insuficiente ou nula, optam pelo registro formal, pela variedade regional ou pelo dialeto.

Esses resultados levam a pensar que, para que possa ser desenvolvida a competência sociolinguística, seria necessário prever mais espaço para essa dimensão linguística nas aulas de uma segunda língua e nos livros didáticos. Em especial, tendo em vista a complexidade do quadro linguístico da Itália contemporânea, seria desejável que os aprendizes aprendessem não apenas registros e variedades "médias", mas também que entrassem em contato com a pluralidade de variedades regionais e de registros, além de desenvolver a capacidade de reconhecer os dialetos como "outras" línguas. A Itália linguística "real" é feita de tudo isso e aprender a (re)conhecer apenas uma pequena parte de sua complexidade significaria perder a riqueza que a constitui. 


\title{
VARIETÀ LINGUISTICA E INSEGNAMENTO DELL'ITALIANO: UN'ESPERIENZA IN CLASSE
}

\begin{abstract}
Questo articolo presenta un'indagine, il cui obiettivo centrale è stato verificare se apprendenti brasiliani, che studiano l'italiano in contesti di istruzione formale da almeno un anno, possiedono la competenza sociolinguistica ricettiva necessaria a identificare le varietà d'italiano e i dialetti presenti in sei scene di un film italiano. I risultati rivelano che nel gruppo studiato questa competenza non é sufficientemente sviluppata e indicano che sarebbe in generale auspicabile dedicarle più spazio.

PAROLE-CHIAVE: varietà linguistica; insegnamento dell'italiano; competenza sociolinguistica.
\end{abstract}

Recebido em: 04/03/2013

Aprovado em: 12/08/2013 